\title{
Desempenho de novilhos confinados alimentados com silagens de diferentes híbridos de milho
}

\section{Performance of confined steers fed with different corn hybrids silages}

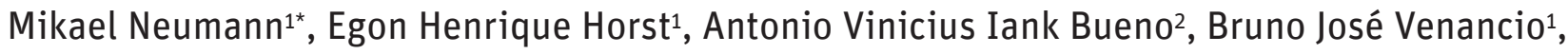 \\ Leslei Caroline Santos ${ }^{1}$, Edelmir Silvio Stadler Júnior ${ }^{1}$ e Guilherme Fernando Mattos Leão ${ }^{2}$
}

\author{
${ }^{1}$ Universidade Estadual do Centro-Oeste (UNICENTRO) - Rua Simeão Camargo Varela de Sá, 03, 85040-080, Guarapuava, Paraná, Brasil \\ 2U niversidade Estadual de Maringá (UEM) - Avenida. Colombo, 5790, 87020-900, Maringá, Paraná, Brasil \\ ( ${ }^{\star}$ E-mail: neumann.mikael@hotmail.com) \\ http://dx.doi.org/10.19084/RCA17126
}

Recebido/received: 2017.05.22

Recebido em versão revista/received in revised form: 2017.11.02

Aceite/accepted: 2017.11.15

\section{R E S U M O}

Objetivou-se avaliar a ingestão de matéria seca, ganho de peso diário, conversão alimentar, digestibilidade e as características da carcaça de novilhos alimentados com dietas à base de silagens de dois híbridos de milho. Os tratamentos foram as silagens de milho provenientes dos híbridos LG6030 PRO e P30B39H. O delineamento experimental foi o inteiramente casualizado, com seis repetições, em esquema de parcelas subdivididas no tempo, em três períodos de avaliação. Animais alimentados com a silagem de milho LG6030 PRO tiveram maior $(P<0,05)$ ganho médio de peso e melhor conversão alimentar. O tipo de silagem não alterou $(P>0,05)$ a ingestão de matéria seca, ganho médio de carcaça e ganho de carcaça no período de terminação. Contudo, com o hibrido LG 6030 PRO houve melhor eficiência de transformação da matéria seca consumida em carcaça, apesar de menor eficiência de transformação do ganho de peso em carcaça $(73,7$ contra 76,9\%) comparativamente com a dieta com silagem de P30B39H. Além disso, a digestibilidade aparente foi maior $(\mathrm{P}<0,05)$ para silagem de milho do híbrido LG6030 PRO, obtendo eficiência de digestão 3,4\% superior. Os componentes de rendimento não integrantes da carcaça não foram alterados em função das variações dietéticas das silagens avaliadas. Sendo assim, recomenda-se o híbrido LG6030 PRO para produção de silagem.

Palavras-chave: conversão alimentar, eficiência alimentar, ganho de peso médio diário, ingestão de matéria seca, rendimento de carcaça.

\begin{abstract}
A B S T R A C T
This work aimed to evaluate the dry matter consumption, daily weight gain, feed conversion, digestibility and carcass characteristics of confined steers fed with silages from different corn hybrids. The treatments were the silages from the hybrids LG6030 PRO and P30B39H. The experimental design was totally randomized, with 6 repetitions, in a split-plot scheme, in three evaluation periods. Animals fed with silage from hybrid LG6030 PRO showed a higher daily weight gain and better food conversion. The silage type did not alter $(P>0.05)$ dry matter consumption, average carcass gain and carcass gain during the finishing period. However, the hybrid LG6030 PRO improved the efficiency transformation of consumed dry matter into carcass, despite the decrease of efficiency of transformation of weight gain into carcass (73,7 vs 76.9\%) comparatively to animals fed with P30B39H silage. Diets containing the hybrid LG6030 PRO reflected in an increase of $3.4 \%$ of apparent digestibility. There were no differences of non-carcass components yield between the treatments in this experiment. It is recommended LG6030 PRO for silage production.
\end{abstract}

Keywords: dry matter consumption, feed conversion, feed efficiency, average daily gain, carcass yield.

\section{INTRODUÇÃO}

O confinamento de ruminantes é utilizado como ferramenta para elevar o ganho de peso dos animais em terminação, promovendo assim redução do tempo dos animais na propriedade. Contudo, o uso de tal estratégia demanda maiores investimentos, tanto em termos de estrutura como 
também com relação a alimentação. Neste âmbito, prioriza-se o uso de alimentos que tenham potencial agronômico e alta qualidade nutricional, sendo a silagem de milho material de destaque (Oliveira et al., 2011).

Todavia, para a confecção de silagem de qualidade, nota-se que existem vários híbridos disponíveis no mercado, sendo necessário critério na sua escolha. Deste modo, ensaios conduzidos recentemente avaliando híbridos visando a produção de silagem apontam como principais critérios para a determinação assertiva na escolha: a produtividade de matéria seca por hectare, com vistas a diluir os custos de produção do alimento; participação dos grãos na base seca (acima de 30\%); boa digestibilidade da fração fibrosa, baixos teores de fibra em detergente neutro (FDN; $<50 \%$ ) e fibra em detergente ácido (FDA; <32\%); além de altos teores de nutrientes digestíveis totais (NDT), priorizando valores acima de 65\% (Vieira et al., 2013; Tres et al., 2014).

Entretanto, primordialmente, ressalta-se a importância da resposta animal a tais fatores. Mesmo que, em muitas situações, as características fermentativas e nutricionais sejam semelhantes, a hipótese de existirem diferenças na resposta animal, pode ser o parâmetro determinante para o sucesso ou insucesso de sistemas produtivos (Rosa et al., 2004; Cândido et al., 2015).

Dentro do exposto, este trabalho teve por objetivo avaliar a ingestão, o desempenho, a digestibilidade e as características da carcaça de novilhos confinados, alimentados com silagens de diferentes híbridos de milho.

\section{MATERIAL E MÉTODOS}

\section{Descrição do local}

O experimento se desenvolveu nas instalações do Núcleo de Produção Animal (NUPRAN) do Setor de Ciências Agrárias e Ambientais da Universidade Estadual do Centro-Oeste (UNICENTRO), em Guarapuava, PR. O clima da região de Guarapuava, $\mathrm{PR}$, é do tipo $\mathrm{Cfb}$ (subtropical mesotérmico úmido), sem estação seca, com verões frescos e inverno moderado conforme a classificação de Köppen, em altitude de aproximadamente $1.100 \mathrm{~m}$, precipitação média anual de $1.944 \mathrm{~mm}$, temperatura média mínima anual de $12,7^{\circ} \mathrm{C}$, temperatura média máxima anual de $23,5^{\circ} \mathrm{C}$ e umidade relativa do ar de $77,9 \%$.

\section{Tratamentos}

As dietas experimentais foram divididas em dois tratamentos: LG6030 PRO - Dieta contendo silagem de milho com híbrido LG6030 PRO e P30B39H - Dieta contendo silagem de milho com híbrido P30B39H.

\section{Obtenção do material experimental}

Para produção das silagens, foram utilizadas áreas delimitadas de terras com boas características de aptidão de uso para o cultivo do milho, no Núcleo de Produção Animal lotado no Setor de Ciências Agrárias e Ambientais da Universidade Estadual do Centro Oeste do Paraná (UNICENTRO). O solo da área experimental é classificado como Latossolo Roxo e a área experimental vem sendo utilizada nos últimos anos com pastagens de ciclo anual na estação de inverno, e lavouras de milho e soja na estação de verão, recebendo a cada estação de cultivo, adubações de fósforo e potássio, conforme as Recomendações de Adubação e Calagem para os Estados do Rio Grande do Sul e Santa Catarina (1995).

A lavoura de milho (Zea mays L.) dos híbridos LG6030 PRO e do P30B39 H, ambos caracterizados pelo ciclo FAO 500, foram implantadas na segunda quinzena de setembro de 2014, em sistema de plantio direto, em sucessão a cultura da aveia, a qual foi dessecada com herbicida a base de glifosate (Produto comercial Roundup WG: 1,5 L/ha). No plantio se utilizou espaçamento entre linhas de $0,8 \mathrm{~m}$, profundidade de semeadura aproximada de $4 \mathrm{~cm}$ e distribuição de sementes por metro linear visando densidades finais de 75 mil plantas ha-1. A adubação de base foi constituída de $500 \mathrm{~kg} \mathrm{ha}^{-1}$ do fertilizante NPK na formulação 08-20-20 $\left(\mathrm{N}-\mathrm{P}_{2} \mathrm{O}_{5}-\mathrm{K}_{2} \mathrm{O}\right)$, e em cobertura, utilizou-se ureia (45-00-00) na dose de $500 \mathrm{~kg} \mathrm{ha}^{-1}$. Os demais tratos culturais do milho foram realizados mediante laudo técnico das lavouras. 
A cultura de milho foi colhida no estádio reprodutivo de grão duro, onde os silos utilizados na confecção e armazenamento das silagens foram do tipo trincheira com as dimensões de $4 \mathrm{~m}$ de largura, $1 \mathrm{~m}$ de altura e $10 \mathrm{~m}$ de comprimento, vedado e protegido com polietileno de dupla face de $150 \mu \mathrm{m}$.

A ensilagem da planta de milho foi realizada no dia 25 de janeiro de 2015, sendo que o corte foi à $15 \mathrm{~cm}$ do solo, com ensiladeira regulada para gerar um tamanho médio de partícula variando entre $0,4 \mathrm{a} 0,6 \mathrm{~cm}$. A massa foi sendo acomodada e compactada nos silos, onde posteriormente, ao final do processo, foi realizado o fechamento do silo com lona plástica grossa (200 micras). As silagens permaneceram estocadas por um período de 30 dias. Após isso, os silos foram então abertos.

\section{Análises da composição química}

Amostras das silagens e do concentrado, utilizadas na alimentação dos animais, foram pesadas e pré-secadas em estufa de ar forçado a $55^{\circ} \mathrm{C}$ por 72 horas, sendo sequencialmente retiradas da estufa e pesadas novamente para determinação do teor de matéria parcialmente seca e moída em moinho tipo "Wiley", com peneira de malha de $1 \mathrm{~mm}$.

Nas amostras pré-secas foram determinadas a matéria seca total (MST) em estufa a $105^{\circ} \mathrm{C}$, proteína bruta (PB) pelo método micro Kjeldahl e matéria mineral $(\mathrm{MM})$ por incineração a $550^{\circ} \mathrm{C}$ (4 horas), conforme AOAC (1995). Também foram determinados os teores de FDN, conforme Van Soest et al. (1991), utilizando-se $\alpha$ amilase termo-estável (Termamyl 120L, Novozymes Latin América Ltda.) e de FDA segundo Goering e Van Soest (1970). Os teores de NDT foram obtidos via equação [NDT, \% = 87,84 - $(0,70 \times$ FDA $)$ ] sugerida por Bolsen (1996).

\section{Alimentos e alimentação}

O experimento teve duração de 104 dias, sendo 20 dias de adaptação dos animais às dietas e instalações experimentais e, sequencialmente, três períodos de avaliação de 28 dias. Os animais foram terminados em confinamento, sendo alimentados, na forma ad libitum, duas vezes ao dia, às 6:00 e às 17:30 horas.

As dietas foram formuladas com base de uma mistura homogênea entre silagem de milho e concentrado comercial, em uma constante relação de $50 \%$ de volumoso e $50 \%$ de concentrado, na base seca da dieta experimental, se valendo como base de exigências o NRC (1996). A preparação do concentrado foi realizada na cooperativa Agrária Entre Rios (Guarapuava-PR), utilizando os seguintes alimentos: farelo de soja, casca de soja, radícula de cevada, grãos de milho moído, calcário calcítico, fosfato bicálcico, sal comum, ureia, monensina sódica e premix vitamínico-mineral. No Quadro 1 apresenta-se a composição química dos alimentos utilizados na alimentação dos animais.

Quadro 1 - Composição química dos alimentos utilizados na alimentação dos animais, com base na matéria seca

\begin{tabular}{lccc}
\hline \multirow{2}{*}{ Parâmetro } & \multicolumn{3}{c}{ Silagem de milho } \\
\cline { 2 - 4 } & $\begin{array}{c}\text { LG6030 } \\
\text { PRO }\end{array}$ & $\begin{array}{c}\text { P30B39 } \\
\text { H }\end{array}$ & $\begin{array}{c}\text { Concen- } \\
\text { trado }\end{array}$ \\
\hline Matéria seca, \% & 40,19 & 37,66 & 89,59 \\
Matéria mineral, \% & 2,24 & 2,17 & 9,68 \\
Proteína bruta, \% & 5,83 & 4,97 & 21,33 \\
Fibra em detergente neutro, \% & 40,51 & 47,68 & 29,31 \\
Fibra em detergente ácido, \% & 23,95 & 24,69 & 13,41 \\
Nutrientes digestíveis totais, \% & 71,07 & 70,56 & 75,60 \\
Ca, \% & 0,12 & 0,13 & 1,67 \\
P, \% & 0,21 & 0,25 & 0,58 \\
\hline
\end{tabular}

A ingestão voluntária dos alimentos foi registrada diariamente, pela pesagem da quantidade oferecida e das sobras do dia anterior. O ajuste no fornecimento da quantidade das silagens de milho e do concentrado foi realizado diariamente, considerando uma sobra de $5 \%$ da matéria seca oferecida em relação à consumida, com vistas a não se gerar restrições a ingestão do animal.

\section{Avaliações de desempenho animal}

O experimento utilizou 24 novilhos inteiros cruza $1 / 2$ Angus, com idade média de 12 meses e peso vivo médio inicial de $372 \mathrm{~kg}$, que foram vermifugados e equilibrados por peso e condição corporal para 
cada baia. Dessa forma, os animais foram pesados, após jejum de sólidos de 12 horas, no início e fim do período experimental, com pesagens intermediárias a cada 28 dias.

As variáveis avaliadas, nos três períodos de avaliação, foram ingestão média diária de matéria seca (CMS) em kg animal-1, mensurado através da diferença entre a quantidade diária de alimento fornecido e a quantidade das sobras de alimento do dia anterior. O CMS por $100 \mathrm{~kg}$ de peso vivo (CMSP) expresso pela razão entre CMS e o peso corporal (PC) médio dos 28 dias, multiplicado por 100 (CMSP=CMS $\div \mathrm{PC} \times 100)$. O ganho de peso médio diário (GMD) foi calculado pela diferença entre o peso corporal final e o inicial do período experimental, dividido por 28, e a conversão alimentar (CA) foi estipulada como (CMS/GMD).

A partir dos dados de GMD, CMS, e peso de carcaça quente (PCQ), foram calculados o ganho de carcaça total (GCT), ganho de carcaça diário (GCD) e a eficiência de transformação do ganho de peso em carcaça (\%) (ETC). O GCT foi calculado pela diferença entre o PCQ e o peso de carcaça inicial (PCi), que foi estimado considerando rendimento de carcaça inicial de 50\% (PCi $=$ PV inicial $\times$ $0,50)$. O GCD foi calculado com base no período de 84 dias de confinamento $(\mathrm{GCD}=\mathrm{GCT} \div 84)$. A ETC foi calculada pela relação entre o GCD e o CMSD $(\mathrm{ETC}=\mathrm{GMD} \div \mathrm{GCD})$.

As determinações da digestibilidade aparente das dietas experimentais foram realizadas na fase mediana da terminação dos animais em confinamento, onde foi mensurada a ingestão diária de alimentos e de sobras de três dias consecutivos (72 horas), juntamente com coleta total de fezes produzidas pelos animais de cada baia para cada determinação.

O delineamento experimental foi o inteiramente casualizado, composto por dois tratamentos, com seis repetições, onde cada repetição foi uma baia com dois animais, num esquema de parcelas subdivididas no tempo, em três períodos de avaliação. Os dados coletados para cada variável foram submetidos à análise de variância com comparação das médias a 5\% de significância, por intermédio do programa estatístico SAS (1993).
A análise de cada variável seguiu o modelo estatístico: $Y_{\mathrm{ijk}}=\mu+{ }_{S} \mathrm{i}+{ }_{\mathrm{Pj}}+\left(\mathrm{S}_{\mathrm{i}}{ }^{*} \mathrm{P}_{\mathrm{j}}\right)_{\mathrm{k}}+\mathrm{E}_{\mathrm{ij} \mathrm{j}}$; onde: $\mathrm{Y}_{\mathrm{ijk}}=$ Variáveis dependentes; $\mu=$ Média geral de todas as observações; ${ }_{\mathrm{Si}}=$ Efeito da silagem de ordem "i", sendo 1 = LG6030 PRO e 2 = P30B39 H; ${ }_{\mathrm{p}} \mathrm{j}$ = Efeito do período de confinamento de ordem "j", sendo $1=$ primeiro período, 2 = segundo período e $3=$ terceiro período; $\left(\mathrm{S}_{\mathrm{i}}{ }^{*} \mathrm{P}_{\mathrm{j}}\right)_{\mathrm{k}}=$ efeito da interação entre silagem de milho de ordem "i" e período de confinamento de ordem "j"; e $E_{\mathrm{ij}}=$ Efeito aleatório residual.

\section{Avaliações de carcaça e componentes não integrantes}

Ao término do experimento, os animais foram submetidos à um jejum de sólidos de 12 horas para que após isso os mesmos pudessem ser pesados e encaminhados ao abate obtendo-se o peso de fazenda. Os abates seguiram o fluxo normal de um abatedouro e as carcaças foram identificadas, lavadas, pesadas, e resfriadas a $-2^{\circ} \mathrm{C}$ por 24 horas, conforme as metodologias sugeridas por Muller (1987).

Nas carcaças resfriadas mensurou-se rendimento de carcaça (obtido pela relação entre pesos de carcaça quente e resfriada), espessura de gordura subcutânea na 12. a costela, assim como foram mensuradas cinco medidas de desenvolvimento: comprimento de carcaça, que é a distância entre o bordo cranial medial do osso púbis e o bordo cranial medial da primeira costela; comprimento de perna, que é a distância entre a borda cranial medial do osso púbis e a articulação tíbio-tarsiana; comprimento de braço, que é a distância entre a tuberosidade do olecrano e a articulação rádio-carpiana; perímetro de braço, obtido na região mediana do braço circundando com uma fita métrica; e a espessura do coxão, medida por intermédio de compasso, perpendicularmente ao comprimento de carcaça, tomando-se a maior distância entre o corte que separa as duas meias carcaças e os músculos laterais da coxa, tal como descrito por Muller (1987).

No momento do abate, também foi realizada a caracterização das partes do corpo não-integrantes da carcaça dos novilhos abatidos, por meio da coleta dos pesos dos seguintes componentes: cabeça, língua, rabo, testículos, patas e couro 
(denominados componentes externos); coração, rins, fígado, baço, pulmões, rúmen-retículo cheios, rúmen-retículo vazios, abomaso cheio, abomaso vazio e intestinos cheios (denominados órgãos vitais).

Para os parâmetros relativos às características da carcaça e partes do corpo não-integrantes da carcaça, o delineamento experimental foi o inteiramente casualizado, composto por dois tratamentos, com seis repetições, onde cada repetição foi representada por uma baia. Os dados coletados para cada variável foram submetidos à análise de variância com comparação das médias a 5\% de significância, por intermédio do programa estatístico SAS (1993).

A análise de cada variável seguiu o modelo estatístico: $Y_{i j}=\mu{ }_{S i}+E_{i j}$; onde: $Y_{i j}=$ Variáveis dependentes; $\mu=$ Média geral de todas as observações; $\mathrm{Si}_{\mathrm{i}}=$ Efeito dos tratamentos; $\mathrm{E}_{\mathrm{ij}}=$ Efeito aleatório residual.

\section{RESULTADOS E DISCUSSÃO}

O resumo da análise da variância contido no Quadro 2 indica que não houve interação significativa entre híbrido de milho e período de confinamento para a ingestão diária de matéria seca (em $\mathrm{kg} \mathrm{dia}^{-1}$ e por $100 \mathrm{~kg}$ de peso vivo), assim como para os parâmetros ganho médio diário e conversão alimentar. Contudo, houve diferença estatística entre híbridos $(\mathrm{P}<0,05)$ referentes aos dados de ganho de peso médio diário, conversão alimentar e ingestão diária de MS dos novilhos confinados.
$\mathrm{Na}$ média geral, animais alimentados com a silagem proveniente do hibrido de milho LG6030 PRO apresentaram maior $(\mathrm{P}<0,05)$ ganho médio de peso e melhor conversão alimentar na ordem de $13,22 \%$ e $23,67 \%$ respectivamente, em relação à dieta com silagem de P30B39 H (Quadro 3).

Não foram observadas diferenças, entre os híbridos avaliados, para a ingestão de MS, expressos em kg de MS por $100 \mathrm{~kg}$ peso vivo (PV), assim como entre períodos. Contudo, observou-se um aumento do consumo de MS diário, nota-se também um aumento no avanço do primeiro período $\left(8,52 \mathrm{~kg} \mathrm{dia}^{-1}\right)$ para o terceiro período de confinamento $\left(10,17 \mathrm{~kg} \mathrm{dia}^{-1}\right)$, com valor intermediário e distinto no segundo período $\left(9,69 \mathrm{~kg} \mathrm{dia}^{-1}\right)$ independente do tipo de silagem fornecida, não havendo diferença significativa entre os híbridos (Quadro 3).

Tal fato se deve ao aumento do peso vivo dos animais, uma vez que com o ganho de massa corpórea estes passam a consumir maior quantidade de alimento em termos absolutos.

Além disto, observou-se maior digestibilidade aparente da matéria seca para o híbrido LG6030 PRO na ordem de 3,4\% (Quadro 4). Tal fato pode estar aliado a digestibilidade da fração fibrosa do alimento, em especial pelo baixo teor em FDN. Foi demostrado que mesmo para híbridos de milho cultivados e colhidos sobre condições semelhantes, há diferenças com relação à digestibilidade da FDN (Mello et al., 2005; Ribas et al., 2007). A maior digestibilidade da fração FDN pode implicar em maior quantidade de substrato passível de sofrer fermentação ruminal, aumentando assim a quantidade de

Quadro 2 - Resumo da análise de variância das variáveis relacionadas ao desempenho de novilhos terminados em confinamento e alimentados com silagens de diferentes híbridos de milho, por períodos de avaliação

\begin{tabular}{lccccccccc}
\hline Fator de & GL & \multicolumn{4}{c}{ Quadrado médio } & \multicolumn{4}{c}{ Probabilidade (P<0,05) } \\
\cline { 3 - 9 } Variação & & GMD & CMSD & CMSP & CA & GMD & CMSD & CMSP & CA \\
\hline Hibrido (H) & 1 & 0,393 & 1,326 & 0,165 & 26,010 & 0,042 & 0,199 & 0,082 & 0,012 \\
Período (P) & 2 & 0,021 & 8,644 & 0,028 & 2,940 & 0,832 & $>0,001$ & 0,537 & 0,456 \\
HP & 2 & 0,200 & 0,676 & 0,034 & 7,394 & 0,188 & 0,427 & 0,464 & 0,149 \\
Erro & & 0,113 & 0,772 & 0,044 & 3,645 & - & - & - & - \\
$\mathrm{R}^{2}$ & - & 0,197 & 0,463 & 0,180 & 0,299 & - & - & - & - \\
CV, \% & - & 23,18 & 9,29 & 9,56 & 27,41 & - & - & - & - \\
Média & - & 1,451 & 9,46 & 2,19 & 6,96 & - & - & - & - \\
\hline
\end{tabular}

GMD = ganho de peso médio diário (kg.dia-1); CSMD = consumo de matéria seca (kg.animal dia-1); CMSP = consumo de matéria seca por 100 kg de peso vivo; CA = conversão alimentar. 
Quadro 3 - Ganho de peso médio diário, consumos de matéria seca e conversão alimentar de novilhos terminados em confinamento e alimentados com silagens de diferentes híbridos de milho, conforme os períodos de avaliação

\begin{tabular}{|c|c|c|c|c|}
\hline \multirow[b]{2}{*}{$\begin{array}{l}\text { Dieta experimental } \\
\text { (Silagem de milho) }\end{array}$} & \multicolumn{3}{|c|}{ Período de Confinamento } & \multirow[b]{2}{*}{ Média } \\
\hline & $\begin{array}{l}1^{\circ} \text { Período } \\
\text { (1-28 dias) }\end{array}$ & $\begin{array}{l}2^{\circ} \text { Período } \\
\text { (29-56 dias) }\end{array}$ & $\begin{array}{l}3^{\circ} \text { Período } \\
\text { (57-84 dias) }\end{array}$ & \\
\hline & \multicolumn{4}{|c|}{ Ganho de peso médio diário, $\mathrm{kg}$ animal dia ${ }^{-1}$} \\
\hline LG6030 PRO & 1,65 & 1,47 & 1,54 & $1,56 \mathrm{~A}$ \\
\hline Р30В39 H & 1,15 & 1,47 & 1,42 & $1,36 \mathrm{~B}$ \\
\hline \multirow[t]{2}{*}{ Média } & 1,40 & 1,47 & 1,48 & \\
\hline & \multicolumn{4}{|c|}{ Consumo de matéria seca, $\mathrm{kg}$ animal dia-1 } \\
\hline LG6030 PRO & 8,48 & 9,61 & 9,70 & 9,27 \\
\hline Р30В39 H & 8,55 & 9,76 & 10,63 & 9,65 \\
\hline \multirow[t]{2}{*}{ Média } & $8,52 \mathrm{c}$ & $9,69 \mathrm{~b}$ & 10,17 a & \\
\hline & \multicolumn{4}{|c|}{ Consumo de matéria seca, $\mathrm{kg}$ de MS por $100 \mathrm{~kg}$ de peso vivo ${ }^{-1}$} \\
\hline LG6030 PRO & 2,15 & 2,20 & 2,02 & 2,12 \\
\hline Р30B39 H & 2,20 & 2,29 & 2,28 & 2,26 \\
\hline \multirow[t]{2}{*}{ Média } & 2,18 & 2,24 & 2,15 & \\
\hline & \multicolumn{4}{|c|}{ Conversão alimentar, kg de MS Ganho de peso diário-1 } \\
\hline LG6030 PRO & 5,36 & 6,43 & 6,56 & $6,11 \mathrm{~B}$ \\
\hline Р30В39 H & 8,58 & 6,51 & 8,36 & $7,81 \mathrm{~A}$ \\
\hline Média & 6,97 & 6,47 & 7,46 & \\
\hline
\end{tabular}

Médias, seguidas por letras maiúsculas, na coluna, diferem entre si pelo Teste $\mathrm{F}$ a $5 \%$.

Médias, seguidas por letras minúsculas, na linha, diferem entre si pelo Teste Tukey a $5 \%$.

energia disponível ao organismo do animal, o que se reflete na melhoria do seu desempenho (Teixeira et al., 2007; Murta et al., 2011).

Contudo, não houve efeito do tipo de silagem nos parâmetros relativos à produção média de fezes, assim como no teor de MS das fezes (Quadro 4).

Quadro 4 - Teor de matéria seca, produção média de fezes e digestibilidade aparente das dietas de novilhos terminados em confinamento e alimentados com silagens de diferentes híbridos de milho

\begin{tabular}{lccc}
\hline $\begin{array}{c}\text { Dietas experimentais } \\
\text { (Silagem de milho) }\end{array}$ & $\begin{array}{c}\text { Matéria seca } \\
\text { das fezes } \\
(\%)\end{array}$ & $\begin{array}{c}\text { Produção } \\
\text { de fezes } \\
\text { (kg dia de MS } \text {-1) }^{\text {( ) }}\end{array}$ & $\begin{array}{c}\text { Digestibilidade } \\
\text { aparente da dieta } \\
(\%)\end{array}$ \\
\hline LG6030 PRO & 17,52 & 2,63 & $72,92 \mathrm{a}$ \\
P30B39 H & 17,13 & 2,78 & $70,52 \mathrm{~b}$ \\
Média & 17,33 & 2,70 & 71,72 \\
Valor de P & 0,078 & 0,142 & 0,049 \\
CV (\%) & 3,78 & 8,42 & 1,55 \\
\hline
\end{tabular}

Médias, seguidas por letras minúsculas, na coluna, diferem entre si pelo Teste F a $5 \%$.

$\mathrm{CV}=$ Coeficiente de variação.
A melhor digestibilidade, e por consequência, maior ganho médio diário apresentados pelos animais que consumiram a silagem do hibrido LG6030 PRO, influenciaram de maneira positiva os parâmetros GCD (1,139 contra 1,034 $\left.\mathrm{kg} \mathrm{dia}^{-1}\right)$, GCT (95,6 contra 86,7 kg) (Quadro 5). Apesar de tais resultados, os animais que receberam silagens

Quadro 5 - Parâmetros relacionados com a produção de carcaça de novilhos terminados em confinamento e alimentados com silagens de diferentes híbridos de milho

\begin{tabular}{lccc}
\hline $\begin{array}{l}\text { Dietas experimentais } \\
\text { (Silagens de milho) }\end{array}$ & $\begin{array}{c}\text { GCD } \\
\left(\mathbf{k g ~ d i a}^{-1}\right)\end{array}$ & $\begin{array}{c}\text { GCT } \\
(\mathbf{k g})\end{array}$ & $\begin{array}{c}\text { ETC } \\
\mathbf{( \% )}\end{array}$ \\
\hline LG6030 PRO & $1,139 \mathrm{a}$ & $95,6 \mathrm{a}$ & $73,7 \mathrm{~b}$ \\
P30B39 H & $1,034 \mathrm{~b}$ & $86,7 \mathrm{~b}$ & $76,9 \mathrm{a}$ \\
Média & 1,086 & 91,1 & 75,3 \\
Valor de P & 0,047 & 0,045 & 0,012 \\
CV (\%) & 12,01 & 12,03 & 4,66 \\
\hline
\end{tabular}

GCD = Ganho médio de carcaça (kg dia-1); GCT = Ganho médio de carcaça em $\mathrm{kg}$ equivalente ao período de 84 dias de confinamento; ETC = eficiência de transformação do ganho de peso em carcaça (\%)

Médias, seguidas por letras minúsculas, na coluna, diferem entre si pelo Teste Tukey a $5 \%$.

$\mathrm{CV}=$ Coeficiente de variação. 
Quadro 6 - Características da carcaça de novilhos terminados em confinamento e alimentados com silagens de diferentes híbridos de milho

\begin{tabular}{|c|c|c|c|c|c|}
\hline \multirow[t]{2}{*}{ Parâmetro } & \multicolumn{2}{|c|}{ Dietas experimentais } & \multirow[t]{2}{*}{ Média } & \multirow{2}{*}{$\begin{array}{c}\text { Valor de } \\
\text { P }\end{array}$} & \multirow{2}{*}{$\begin{array}{l}\text { CV } \\
(\%)\end{array}$} \\
\hline & LG6030 PRO & P30B39 H & & & \\
\hline Peso de carcaça quente, $\mathrm{kg}$ & 281,3 & 272,9 & 277,2 & 0,103 & 3,52 \\
\hline Rendimento de carcaça, \% & 56,15 & 56,07 & 56,11 & 0,072 & 1,01 \\
\hline \multicolumn{6}{|l|}{ Espessura de gordura, mm } \\
\hline Longissimus dorsi & 4,49 & 4,46 & 4,47 & 0,8630 & 16,68 \\
\hline Traseiro & 4,50 & 4,30 & 4,30 & 0,6447 & 21,01 \\
\hline Costilhar & 6,30 & 5,75 & 6,03 & 0,7530 & 16,21 \\
\hline Dianteiro & 3,65 & 3,60 & 3,63 & 0,9405 & 30,44 \\
\hline Comprimento de carcaça, $\mathrm{cm}$ & 131,8 & 132,1 & 131,9 & 0,5872 & 2,44 \\
\hline Espessura de coxão, cm & 19,3 & 20,0 & 19,6 & 0,3690 & 6,70 \\
\hline Comprimento de braço, $\mathrm{cm}$ & 39,1 & 39,6 & 39,3 & 0,0849 & 2,05 \\
\hline Perímetro de braço, $\mathrm{cm}$ & 42,4 & 42,8 & 42,6 & 0,0994 & 1,92 \\
\hline
\end{tabular}

CV = Coeficiente de variação.

provenientes do hibrido LG6030 PRO apresentaram menor $(\mathrm{P}<0,05)$ eficiência de transformação do ganho de peso em carcaça $(73,7$ contra $76,9 \%)$ comparativamente a dieta com silagem de P30B39 H (Quadro 5).

Na média geral, não se observou efeito $(P>0,05)$ do tipo de silagem sobre as características quantitativas da carcaça dos animais quanto ao peso de carcaça quente, ao rendimento de carcaça, assim como no comprimento de carcaça, espessura de coxão, comprimento de braço e perímetro de braço (Quadro 6).

Tais resultados se justificam uma vez que as dietas experimentais são relativamente semelhantes, apresentado diferença de 7,15\% no FDN. Porém alterações no rendimento de carcaça de animais

Quadro 7 - Componentes de rendimento não integrantes da carcaça, expresso em \% do peso vivo, de novilhos terminados em confinamento e alimentados com silagens de diferentes híbridos de milho

\begin{tabular}{|c|c|c|c|c|c|}
\hline \multirow[t]{2}{*}{ Parâmetro } & \multicolumn{2}{|c|}{ Dietas experimentais } & \multirow{2}{*}{$\begin{array}{c}\text { Média } \\
\mathbf{P} \\
\end{array}$} & \multirow{2}{*}{$\begin{array}{c}\text { Valor de } \\
\text { P }\end{array}$} & \multirow{2}{*}{$\begin{array}{l}\text { CV } \\
(\%)\end{array}$} \\
\hline & LG6030 PRO & P30B39 H & & & \\
\hline & & peso vivo ... & & & \\
\hline \multicolumn{6}{|l|}{ Órgãos vitais: } \\
\hline Coração & 0,39 & 0,38 & 0,38 & 0,9695 & 10,86 \\
\hline Fígado & 1,25 & 1,33 & 1,29 & 0,2148 & 7,61 \\
\hline Pulmões & 0,84 & 0,76 & 0,80 & 0,0634 & 4,01 \\
\hline Rins & 0,24 & 0,24 & 0,24 & 0,8630 & 11,33 \\
\hline Baço & 0,40 & 0,44 & 0,42 & 0,1031 & 5,09 \\
\hline Rúmen/retículo cheios & 8,45 & 9,38 & 8,91 & 0,0788 & 20,98 \\
\hline Rúmen/retículo vazios & 1,61 & 1,70 & 1,66 & 0,0727 & 3,29 \\
\hline Abomaso cheio & 0,73 & 0,61 & 0,67 & 0,2966 & 17,17 \\
\hline Abomaso vazio & 0,53 & 0,46 & 0,49 & 0,2356 & 11,45 \\
\hline Intestinos cheios & 5,88 & 5,92 & 5,90 & 0,3934 & 17,05 \\
\hline \multicolumn{6}{|l|}{ Componentes externos: } \\
\hline Cabeça & 2,93 & 2,78 & 2,86 & 0,3455 & 4,21 \\
\hline Língua & 0,20 & 0,18 & 0,19 & 0,0508 & 7,19 \\
\hline Couro & 11,11 & 10,24 & 10,68 & 0,4433 & 7,78 \\
\hline Rabo & 0,29 & 0,29 & 0,29 & 0,7473 & 6,93 \\
\hline Testículos & 0,38 & 0,34 & 0,36 & 0,8375 & 20,09 \\
\hline Patas & 2,38 & 2,39 & 2,38 & 0,1434 & 3,32 \\
\hline
\end{tabular}

$\mathrm{CV}=$ Coeficiente de variação. 
são relatadas caso haja substituição de um volumoso de qualidade nutricional elevada em detrimento de qualidade inferior (Pinto et al., 2010), ao se utilizar animais de grupos genéticos distintos (Marcondes et al., 2011) ou então quando os mesmos apresentam porporção de orgãos internos distintos (Menezes et al., 2007), situações não observadas neste estudo (Quadro 7).

Zanette et al. (2012) relataram diferenças com relação a espessura de gordura e classificação da distribuição da mesma, havendo melhorias nestes aspectos quando são ofertadas silagens com maior digestibilidade da matéria seca. Contudo a espessura de gordura mensurada no Longíssimus dorsi, no traseiro, no costilhar e no dianteiro também não sofreram influência dos tratamentos utilizados neste experimento.

Conforme dados contidos no Quadro 7, os componentes de rendimento não integrantes da carcaça de novilhos terminados em confinamento, expresso em $\%$ do peso vivo, não foram alterados $(P>0,05)$ em função das variações dietéticas das silagens avaliadas. Tal fato pode estar relacionado com a homogeneidade dos animais, sistema de terminação adotado e das dietas utilizadas. Segundo Menezes et al. (2011) o tipo de sistema de terminação (pastagem temperada ou confinamento) foi capaz de alterar o peso do fígado, devido a maior oferta de proteína bruta aos animais consumindo pastagem, o que não ocorreu neste estudo, assim como para o conjunto rúmen retículo e demais órgãos internos. Já Peripolli et al. (2013) observaram que animais terminados em sistemas de pastejo apresentaram peso mais elevado de abomaso, pulmão e rins em comparação a animais confinados.

Somando-se os componentes cabeça, couro e patas, estes representaram valores médios de $15,93 \%$, e semelhantes aos relatados por Menezes et al. (2011) os quais observaram para bovinos em confinamento o valor de $15,1 \%$.

\section{CONCLUSÕES}

O híbrido de milho LG6030 PRO proporcionou silagem com maior digestibilidade aparente em relação ao híbrido P30B39 H, o que impactou em maior ganho de peso, ganho médio de carcaça e melhor conversão alimentar, sem afetar as características da carcaça e de seus componentes não integrantes, podendo por isso, ser recomendado como um bom híbrido para produção de silagem.

\section{REFERÊNCIAS BIBLIOGRÁFICAS}

AOAC (1995) - Official methods of analysis. 16.ed. Washington, D.C.: Association of Official Analytical Chemists, $2000 \mathrm{p}$.

Bolsen, K.K. (1996) - Silage Technology. In: Australian maize conference, 2., 1996, Queensland. Proceedings Queensland: Gatton College.

Cândido, E.P.; Santos, E.E.; Ramos, J.P.F.; Oliveira, J.S.; Pirno, R.M.A.; Perazzo, A.F.; Ramos, R.C.S. \& Freitas, P.M.D. (2015) - Resposta econômica do confinamento de ovinos alimentados com silagens de diferentes cultivares de sorgo. Ciência Rural, vol. 45, n. 1, p. 79-85. http://dx.doi.org/10.1590/0103-8478cr20140493

Goering, H.K. \& Van Soest, P.J. (1970) - Forage fiber analysis: apparatus reagents, procedures and some applications. Washington, D.C. p.379. Agricultural Handbook.

Marcondes, M.I., Valadares Filho, S.C.; Oliveira, I.M.; Paulino, P.V.R.; Valadares, R.F. D. \& Detmann, E. (2011) - Eficiência alimentar de bovinos puros e mestiços recebendo alto ou baixo nível de concentrado. Revista Brasileira de Zootecnia, vol. 40, n. 6, p. 1313-1324.

Mello, R.; Nörnberg, J.L.; Rocha, M.G. \& David, D.B. (2005) - Características produtivas e qualitativas de híbridos de milho para produção de silagem. Revista Brasileira de Milho e Sorgo, vol. 4, n. 1, p. 79-94. http:// dx.doi.org/10.18512/1980-6477/rbms.v4n01p\%25p

Menezes, L.; Restle, J.; Brondani, I.L.; Kuss, F.; Alves Filho, D.C.; Silveira, M. \& Leite, D.T. (2007) - Órgãos internos e trato gastrintestinal de novilhos de gerações avançadas do cruzamento rotativo entre as raças Charolês e Nelore, terminados em confinamento. Revista Brasileira de Zootecnia, vol. 36, n. 1, p. 120-129. http://dx.doi.org/10.1590/S1516-35982007000100015 
Menezes, L.F.; Brondani, I.L.; Restle, J.; Alves Filho, D.C.; Callegaro, A.M. \& Weise, M. (2011) - Características dos componentes não integrantes da carcaça de novilhos superjovens da raça Devon, terminados em diferentes sistemas de alimentação. Arquivo Brasileiro de Medicina Veterinária e Zootecnia, vol. 63, n. 2, p. 372-381. http://dx.doi.org/10.1590/S0102-09352011000200015

Muller, L. (1987) - Normas para avaliação de carcaça e concurso de carcaças de novilhos. 2 ed. Santa Maria: Universidade Federal de Santa Maria, 31p.

Murta, R.M.; Chaves, M.A.; Pires, A.J.V.; Veloso, C. M.; Silva, F. D.; Rocha Neto, A.L. \& Santos, P.D. (2011) - Desempenho e digestibilidade aparente dos nutrientes em ovinos alimentados com dietas contendo bagaço de cana-de-açúcar tratado com óxido de cálcio. Revista Brasileira de Zootecnia, vol. 40, n. 6, p. $1325-1332$.

NRC (1996) - Subcommittee of beef cattle nutrition. (Washington, DC, USA). Nutrient requirement of beef cattle. 7. Ed.; Washington: National Academy Press, National Research Council. 242 p.

Oliveira, M.R.; Neumann, M.; Mendes, M.C.; Faria, M.V. \& Neri, J. (2011) - Resposta econômica na terminação de novilhos confinados com silagens de milho (Zea mays l.), em diferentes estádios de maturação, associadas a dois níveis de concentrado na dieta. Revista Brasileira de Milho e Sorgo, vol. 10, n. 2, p. 87-95. http://dx.doi.org/10.18512/1980-6477/rbms.v10n2p87-95

Peripolli, V.O.L..; Barcellos, J.O.J.; Olmedo, D.A.O.; Lampert, V.D.N. \& Velho, M.M.S. (2013) - Componentes não-integrantes da carcaça de bovinos de três grupos genéticos terminados em confinamento ou pastejo rotacionado com suplementação. Revista Brasileira de Saúde e Produção Animal, vol. 14, n. 1, p. 209-223. http://dx.doi.org/10.1590/S1519-99402013000100020

Pinto, A.P.; Abrahão, J.J.S.; Marques, J.A.; Nascimento, W.G.; Perotto, D. \& Lugão, S.M.B. (2010) - Desempenho e características de carcaça de tourinhos mestiços terminados em confinamento com dietas à base de cana-de-açúcar em substituição à silagem de sorgo. Revista Brasileira de Zootecnia, vol. 39, n. 1, p. 198-203. http://dx.doi.org/10.1590/S1516-35982010000100026

Ribas, M.N.; Gonçalves, L.C.; Ibrahim, G.H. F.; Rodriguez, N.; Borges, A.L.C.C. \& Borges, I. (2007) - Ingestão e digestibilidade aparente de silagens de milho com diferentes graus de vitreosidade no grão. Revista Brasileira de Milho e Sorgo, vol. 6, n. 1, p. 104-115. http://dx.doi.org/10.18512/1980-6477/rbms.v6n01p\%25p

Rosa, J.R.P.; Restle, J.; Silva, J.D.; Pascoal, L.L.; Pacheco, P.S.; Faturi, C. \& Santos, A.D. (2004) - Avaliação da silagem de diferentes híbridos de milho (Zea mays, L.) por meio do desempenho de bezerros confinados em fase de crescimento. Revista Brasileira de Zootecnia, vol. 33, n. 4, p. 1016-1028. http://dx.doi.org/10.1590/ S1516-35982004000400022

SAS (1993) - SAS/STAT user's Guide: statistics, version 6. 4.ed. North Carolina, SAS Institute. vol. 2, 943 p.

Teixeira, R.M.A.; Campos, J.M.S.; Valadares Filho, S.C.; Oliveira, A. S.; Assis, A.J. \& Pina, D.S. (2007) - Ingestão, digestibilidade e desempenho de novilhas alimentadas com casca de café em substituição à silagem de milho. Revista Brasileira de Zootecnia, vol. 36, n. 4, p. 968-977. http://dx.doi.org/10.1590/S1516-35982007000400029

Tres, T.T.; Jobim, C.C.; Pinto, R.J.B.; De Souza Neto, I.L.; Scapim, C.A. \& Da Silva, M.S.J. (2014) - Composição nutricional e digestibilidade "in vitro" de genótipos de milho produzidos em dois anos agrícolas. Semina: Ciências Agrárias, vol. 35, n. 6, p. 3249-3262.

Van Soest, P.J.; Robertson, J.B. \& Lewis, B.A. (1991) - Methods for dietary fiber, neutral detergent fiber, and nonstarch polysaccharides in relation to animal nutrition. Journal of Dairy Science, vol. 74, n. 10, p. 35833597. https://doi.org/10.3168/jds.S0022-0302(91)78551-2

Vieira, V.C.; Martin, T.N.; Menezes, L.F.; Assmann, T.; Ortiz, S., Bertoncelli, P. \& Schimitz, T.H. (2013) - Caracterização bromatológica e agronômica de genótipos de milho para produção de silagem. Arquivo Brasileiro de Medicina Veterinária e Zootecnia, vol.65, n.3, p. 847-856. http://dx.doi.org/10.1590/ S0102-09352013000300034

Zanette, P.; Neumann, M.; Marafon, F.; Maria, F.N. \& Poczyneck, M. (2012) - Características da carcaça de bovinos e digestibilidade de silagens de milho (Zea mays L.) com adição de açúcar ou inoculante enzimo-bacteriano. Revista Brasileira de Milho e Sorgo, vol. 10, n. 3, p. 235-246. http://dx.doi.org/10.18512/1980-6477/rbms. v10n3p235-246 